\title{
Off-Road Motorbike Performance Analysis Using a Rear Semiactive EH Suspension
}

\author{
Jorge de-J. Lozoya-Santos, ${ }^{1}$ Damián Cervantes-Muñoz, ${ }^{2}$ \\ Juan Carlos Tudón-Martínez, ${ }^{1}$ and Ricardo A. Ramírez-Mendoza ${ }^{2}$ \\ ${ }^{1}$ Universidad de Monterrey, Avenida Ignacio Morones Prieto 4500 Poniente, 66238 San Pedro Garza García, NL, Mexico \\ ${ }^{2}$ Escuela de Ingeniería y Ciencias, Tecnológico de Monterrey, Avenida Eugenio Garza Sada 2501 Sur, 64849 Monterrey, NL, Mexico \\ Correspondence should be addressed to Jorge de-J. Lozoya-Santos; jorge.lozoya@udem.edu
}

Received 27 December 2014; Accepted 30 April 2015

Academic Editor: Chao Tao

Copyright (C) 2015 Jorge de-J. Lozoya-Santos et al. This is an open access article distributed under the Creative Commons Attribution License, which permits unrestricted use, distribution, and reproduction in any medium, provided the original work is properly cited.

\begin{abstract}
The topic of this paper is the analysis of a control system for a semiactive rear suspension in an off-road two-wheeled vehicle. Several control methods are studied, as well as the recently proposed Frequency Estimation Based (FEB) algorithm. The motorcycle dynamics, as well as the passive, and semiactive dampers, and the algorithm controlled shock absorber models are loaded into BikeSim, a professional two-wheeled vehicle simulation software, and tested in several road conditions. The results show a detailed comparison of the theoretical performance of the different control approaches in a novel environment for semiactive dampers.
\end{abstract}

\section{Introduction}

The conventional off-road suspensions of cross motorbikes present long travel and they are fully adjustable. The damper (shock absorber) characteristics are changed depending on track features in order to increase the car-driver performance. These changes are based on adjustments of the valve system of the shock [1]. The way these adjustments are done is through a six-position circlip preload adjustment. For each road, the shock absorber must be adjusted according to the experience of the team [2]. This is the current practice in off-road competition. The goal of the tuning is to keep the rear tire in contact with the track surface as well as to avoid as much as possible hard conditions for the rider in the motorbike seat [1].

Semiactive suspensions have been studied in fourwheeled vehicles but have not been thoroughly studied in two-wheeled vehicle applications. These systems offer an attractive alternative in comparison to passive suspensions in applications where comfort, handling, or both are desired because of its relatively low cost, energy consumption and improved performance. They have been available in high-end consumer vehicles (i.e., Cadillac vehicles [3] and Ducati motorbikes [4]) but are often underutilized, as the control algorithm embedded in the Electronic Control Unit (ECU) could be optimized. It is underlined that the application of semiactive suspensions focused on competition performances has not been fully addressed.

The paper presents a study of a passive and a semiactive suspension system in a cross motorcycle, analyzing its performance under several automatic suspension control methods: two state outputs and a classical continuous optimal solution. The contribution of the paper to the current art is the application of semiactive suspension technology in an off-road two-wheeled racing vehicle, which could not only offer an important competitive advantage in the motorbike's performance but also reduce a pilot's possible injuries due to improved comfort during competition.

The paper consists of several sections. Section 2 presents a literature review. The simulation platform is detailed in Section 3; Section 4 covers the methodology; the results are shown in Section 5; the discussion of the results is proposed in Section 6; and Section 7 concludes the paper. The nomenclature is presented in Abbreviation. 


\section{Literature Review}

On a motorcycle, the suspension system is more sophisticated than most automotive systems. Its dynamics are more complex since the ratio between the sprung and unsprung mass is a lot smaller than on a car, making it harder to obtain a good performance [5]. Electronically adjustable systems (ESA, Electronic Suspension Adjustment, DES, Ducati's Electronic Suspension, etc. from Öhlins Mechatronics) have been recently used in motorbikes. These systems work by fine-tuning the fork and shock adjusters using servomotors effectively changing the damping; however, they have slow response times (tenths of a second). Their adaptability is focused to general conditions [6]. In contrast, a semiactive suspension system uses electronically controlled valves inside the shock performing damping changes in milliseconds. This allows a motorbike suspension to react as fast as the road profile changes, which can mean a difference in a race.

A semiactive damper can have fluid-based (viscosity of the fluid changes proportional to an external electronic signal, i.e., magnetorheological [7], electrorheological [8]) and valve-based (changes of the oil flow area inside shock, i.e., electrohydraulic (EH) [7]) technologies. Each technology has different drawbacks when applied to high frequency bandwidth in sport motorbike applications. Commercially, $\mathrm{EH}$ dampers are the first option for motorbikes (Sachs, Marzocchi, and Tenneco) due to their mechanical robustness, linear response to exogenous input, and fast response time (10-30 milliseconds). The reason for this is that the fluidbased semiactive technology is sensible to the tribology of fluids (wear) and to the friction added by the damper seals in high-end applications [9], while valve-based technology only depends on solenoid and mechanical design [5].

The commercial semiactive damping technology for motorcycles has been focused in superbikes (speed) like the 2013 Ducati Multistrada with Ducati Skyhook Suspension (DSS) and the BMW HP4 with Dynamic Damping Control (DDC) being the firsts of its type. The Enduro motorbike from KTM 1290 Super Adventure also has a semiactive suspension. The scientific literature on semiactive suspensions for sport motorcycles has been focused on developments for a MR front suspension [9], a MR rear suspension for an Enduro motorcycle [10], and $\mathrm{EH}$ rear suspensions for hypersport motorcycles $[5,11]$. However, the use of semiactive suspensions in off-road motorbikes has not been studied.

Regarding the control systems of semiactive suspension, there are several approaches. The two-state damping approach has been shown to be more effective and sufficient [12]. Some controllers of this type are the Ground Hook [13], Mixed Skyhook-Acceleration Driven Damping ( $\mathrm{SH}-$ ADD) [12], Mixed-Handling [14], and Mixed 1 Sensor [15]. Another approach is to modify the damping characteristics according to different road irregularity frequencies, which the Frequency Estimation Based (FEB) [16] principle ensures. These controllers are described below.

Ground Hook (GH). The strategy keeps the dynamic tiresurface on low value forces to optimize road holding. It proposes a virtual damper between the wheel and surface parallel to the tire, and the control law is [13]

$$
\begin{array}{ll}
c_{\text {in }}(t)=c \max & \text { if }-\dot{z}_{\mathrm{us}}\left(\dot{z}_{s}-\dot{z}_{\mathrm{us}}\right) \geq 0, \\
c_{\text {in }}(t)=c \min & \text { if }-\dot{z}_{\mathrm{us}}\left(\dot{z}_{s}-\dot{z}_{\mathrm{us}}\right)<0 .
\end{array}
$$

Mixed $S H-A D D$. This strategy requires a two-state damper and is characterized by a design parameter $\alpha$ which represents the desired crossover frequency between SH and ADD. The control law is given by [12]

$$
\begin{array}{ll}
c_{\text {in }}(t)=c \max & \text { if }\left[\left(\ddot{z}^{2}-\alpha^{2} \dot{z}^{2}\right) \leq 0 \cap \dot{z}\left(\dot{z}-\dot{z}_{t}\right)>0\right] \cup\left[\left(\ddot{z}^{2}-\alpha^{2} \dot{z}^{2}\right)>0 \cap \ddot{z}\left(\dot{z}-\dot{z}_{t}\right)>0\right], \\
c_{\text {in }}(t)=c \min & \text { if }\left[\left(\ddot{z}^{2}-\alpha^{2} \dot{z}^{2}\right) \leq 0 \cap \dot{z}\left(\dot{z}-\dot{z}_{t}\right) \leq 0\right] \cup\left[\left(\ddot{z}^{2}-\alpha^{2} \dot{z}^{2}\right)>0 \cap \ddot{z}\left(\dot{z}-\dot{z}_{t}\right) \leq 0\right] .
\end{array}
$$

Mixed 1 Sensor. This strategy requires a two-state damper and requires only a sensor of vertical body motion. The equation simply selects the minimum or the maximum available damping ratio, according to the dominant frequency content of the body vertical movement. The control law is given by [15]

$$
\begin{array}{ll}
c_{\text {in }}(t)=c \max & \text { if } \ddot{z}^{2}-\alpha^{2} \dot{z}^{2}>0, \\
c_{\text {in }}(t)=c \min & \text { if } \ddot{z}^{2}-\alpha^{2} \dot{z}^{2} \leq 0 .
\end{array}
$$

Mixed-Handling. This strategy requires a two-state damper and is characterized by a design parameter $\alpha$ which represents the desired crossover frequency. It is based on the idea of selecting the appropriate damping on the frequency content of the road disturbance. The control law is given by [14]

$$
\begin{array}{ll}
c_{\text {in }}(t)=c \max & \text { if } \ddot{z}^{2}-\alpha^{2} \dot{z}^{2} \leq 0, \\
c_{\text {in }}(t)=c \text { min } & \text { if } \ddot{z}^{2}-\alpha^{2} \dot{z}^{2}>0 .
\end{array}
$$

FEB. The damping coefficient is adjusted according to the frequency of motion in order to reach the desired vehicle performance. Hence, by having an estimation of $f_{z r}$ it is possible to assign specific electric current values according to a preanalysis of the frequency responses in the performance objectives:

$$
\widehat{f}=\sqrt{\frac{\left(\dot{z}_{1}^{2}+\dot{z}_{2}^{2}+\cdots+\dot{z}_{n}^{2}\right)}{\left(z_{1}^{2}+z_{2}^{2}+\cdots+z_{n}^{2}\right) \cdot 4 \pi^{2}}} .
$$


Table 1 illustrates a look-up table to customize the electric current profile in a semiactive damper according to the bandwidth of control that depends on a frequency estimation. A feature of the classic algorithms ( $\mathrm{SH}, \mathrm{GH}, \mathrm{SH}-\mathrm{ADD}$, etc.) is that these methods have only two output modes: $c_{\max }$ and $c_{\text {min }}$ (maximum and minimum current, resp.). In contrast, the FEB approach is able to apply several damping states according to the road conditions.

As a typical benchmark, the continuous optimal control approach linear quadratic regulator (LQR) [17] is used as the continuous damping control system. The LQR system is a method where state feedback control can be used for the control of semiactive suspensions. First, a linear quadratic regulator is designed for the fully active suspension system (a suspension system with a high-bandwidth actuator incorporated in parallel to the main spring and damper), and then the desired forces are clipped to the possibilities of the semiactive damper. A continuous electronic signal is applied. The dynamics of the quarter of car is expressed in the following state space equations:

$$
\begin{aligned}
& \dot{x}=A x+B u+C_{z r} w, \\
& y=M x+N u,
\end{aligned}
$$

where

$$
\begin{aligned}
& A=\left[\begin{array}{cccc}
0 & 0 & -\frac{k_{s}}{m_{s}} & 0 \\
0 & 0 & \frac{k_{s}}{m_{s}} & -\frac{k_{t}}{m_{\mathrm{us}}} \\
1 & -1 & 0 & 0 \\
0 & 1 & 0 & 0
\end{array}\right], \\
& B=\left[\begin{array}{c}
-\frac{1}{m_{s}} \\
\frac{1}{m_{\mathrm{us}}} \\
0 \\
0
\end{array}\right], \\
& C=\left[\begin{array}{c}
-\frac{1}{m_{s}} \\
\frac{1}{m_{\mathrm{us}}} \\
0 \\
0
\end{array}\right] \text {, } \\
& M=\left[\begin{array}{cccc}
0 & 0 & -\frac{k_{s}}{m_{s}} & 0 \\
0 & 0 & 1 & 0 \\
0 & 0 & 0 & 1
\end{array}\right] \text {, } \\
& N=\left[\begin{array}{c}
-\frac{1}{m_{s}} \\
0 \\
0
\end{array}\right] \text {, }
\end{aligned}
$$

TABLE 1: Custom frequency bandwidths with their respective current values for continuous control of the FEB algorithm.

\begin{tabular}{lcccc}
\hline$\widehat{f}(=) \mathrm{Hz}$ & BW1 & BW2 & BW3 & BW4 \\
\hline$I(=) \mathrm{A}$ & $\gamma 1$ & $\gamma^{2}$ & $\gamma^{3}$ & $\gamma 4$ \\
\hline
\end{tabular}

$$
\begin{aligned}
& x=\left[\begin{array}{c}
\dot{z}_{s} \\
\dot{z}_{\mathrm{us}} \\
z_{s}-z_{\mathrm{us}} \\
z_{\mathrm{us}}-z_{r}
\end{array}\right], \\
& u=c\left(\dot{z}_{s}-\dot{z}_{\mathrm{us}}\right), \\
& w=\dot{z}_{r} .
\end{aligned}
$$

It must be noted that the state space input is the force of the semiactive damper. In this paper, the cited control algorithms have been chosen for the performance comparison focused in road holding. It is assumed that all signals needed for each controller can be measured.

\section{Simulation Platform}

The experiment's software-in-the-loop (SiL) simulation platform is composed of Mechanical Simulation BikeSim and MathWorks Matlab. BikeSim is a specialized software tool designed to simulate the dynamic behavior of two-wheeled vehicles, with different characterized motorbike models and a variety of available road conditions. The motorcycle model used is included with BikeSim 3.21 and is highly customizable. For the experiment, the bike's dimensions and the wheel and rear suspension parameters in Figure 1 were used. Matlab is an environment for numerical computation, programming, and a model-based design platform. For the experiment, the software was used as the communication link with BikeSim, by importing different variables information, executing the control systems, and exporting information to BikeSim, Figure 2.

Figure 3 displays an example of the models used in the experiment. Block number 1 represents the BikeSim link to Matlab; block number 2 represents the export variables to the model; blocks in number 3 are variables initializations; block number 4 encloses the damper model and the control system; communication line number 5 is the export information to BikeSim.

The actuators used in the simulation are a symmetrical passive damper and an electrohydraulic (EH) asymmetrical semiactive shock absorber, with a smaller damping coefficient during compression. This technology uses solenoid valves in the main body of the damper and changes the damping ratio by modifying the size of the orifices [18].

The characterized prototype is an asymmetrical damper able to perform under electric currents ranging from $0 \mathrm{~mA}$ 


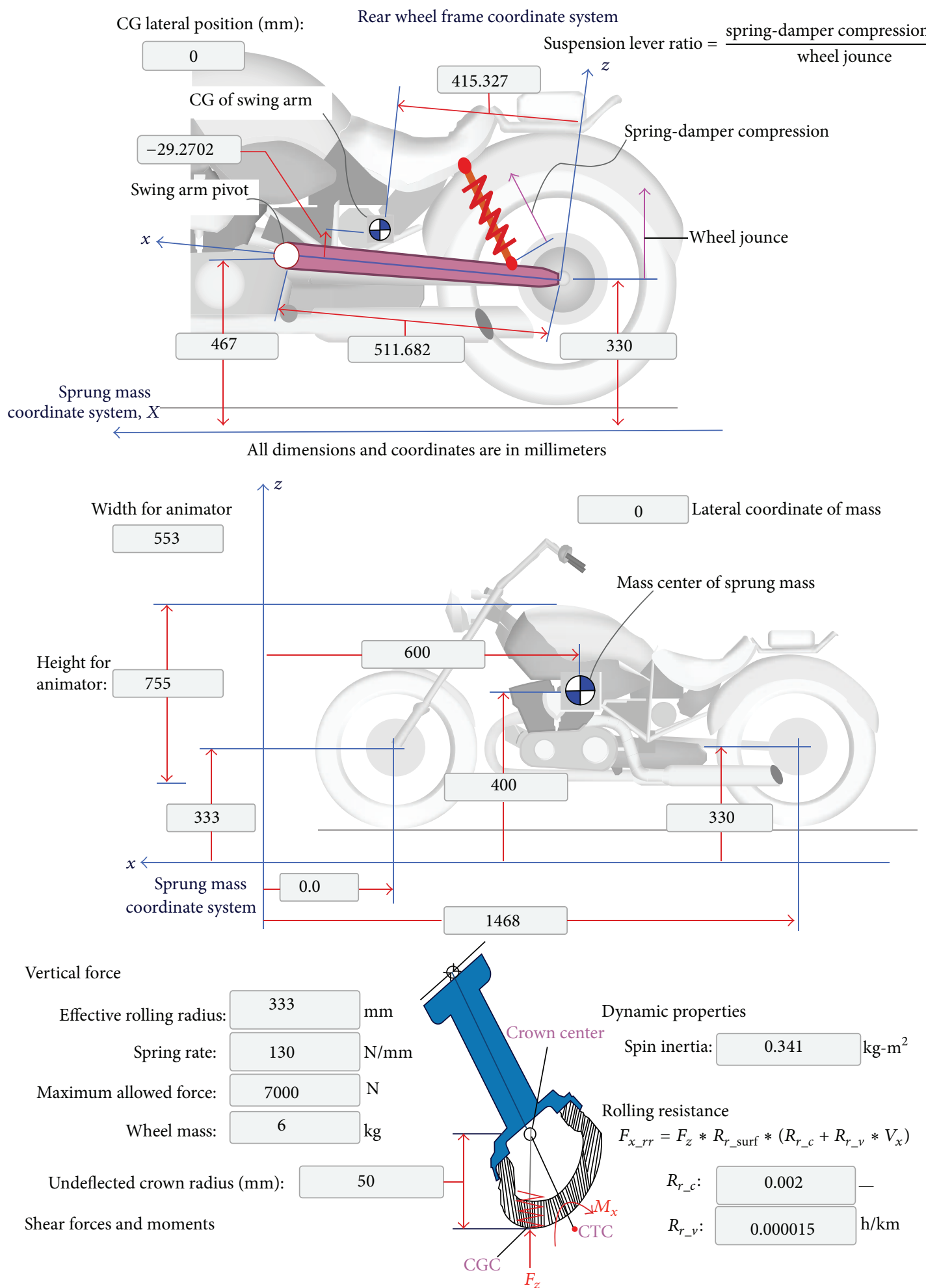

Figure 1: Customizable parameters in BikeSim. 


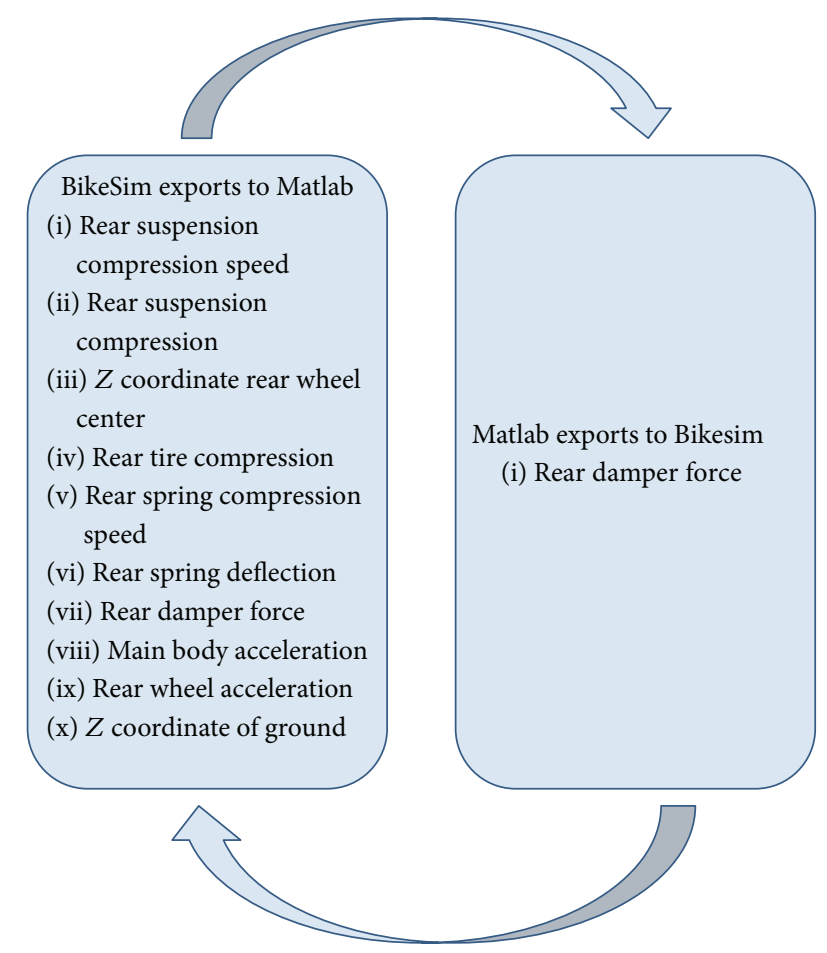

FIgURE 2: BikeSim and Matlab communication process.

(maximum force) to $1800 \mathrm{~mA}$ (minimum force). Its generic model is as follows:

$$
\begin{aligned}
F_{D} & =F_{P+,-}+F_{\mathrm{SA}+,-}, \\
F_{P} & =f_{0}+c_{p} \dot{z}+k_{p} z+m_{D} \ddot{z}+f_{s}+f_{h, z}+f_{h, \ddot{z}}, \\
F_{\mathrm{SA}} & =M g_{\mathrm{SA}}\left[f_{\mathrm{pre}-c, \dot{z}, M}+f_{\mathrm{pre}-c, z}\right],
\end{aligned}
$$

where

$$
\begin{aligned}
f_{s} & =f_{c, s}\left(\frac{r_{s} \dot{z}+h_{s}}{1+\left|r_{s} \dot{z}+h_{s}\right|}\right), \\
f_{h, z} & =f_{h 1}\left(\frac{r_{z} \dot{z}+h_{z} \operatorname{sign}(z)}{1+\left|r_{z} \dot{z}+h_{z} \operatorname{sign}(z)\right|}\right), \\
f_{h, \ddot{z}} & =f_{h 2}\left(\frac{r_{\ddot{z}} \dot{z}+h_{\ddot{z}} \operatorname{sign}(\ddot{z})}{1+\left|r_{\ddot{z}} \dot{z}+h_{\ddot{z}} \operatorname{sign}(\ddot{z})\right|}\right), \\
f_{\mathrm{pre}-c, \dot{z}, M} & =\left(\frac{r_{\dot{z}, M} \dot{z} M}{1+\left|r_{\dot{z}, M} \dot{z} M\right|}\right), \\
f_{\mathrm{pre}-c, z} & =\left(\frac{r_{z, M} z}{1+\left|r_{z, M} z\right|}\right) .
\end{aligned}
$$

Equation (9) describes the passive component of the semiactive damper force, and (10) describes the semiactive component of the damper force. Equation (8) is the sum of these two forces. For detailed information about the $\mathrm{EH}$ damper, see
de-J Lozoya-Santos et al. [19]. Figure 4 shows the simulation of the EH damper using (8) and the passive damper model.

A dynamic filter is added to the model (8) in order to take into account the transient behavior of the damper, Figure 4 . The time constant for the first-order filter is $25 \mathrm{~ms}$ with no gain according to experimental results for a semiactive damper [19].

The parameters in the quarter of vehicle are computed according to the distance between front and rear wheel regarding the center of mass $(60 \%, 40 \%)$, the rear suspension in BikeSim software, and the EH damper model.

\section{Methodology}

A total of six tests are performed to each motorbike suspension configuration. There are two details to observe: (a) the road holding improvement of the off-road motorbike due to a semiactive rear suspension when subjected to race driving conditions and (b) the control methods with dynamic force response and how they exploit the $\mathrm{EH}$ damper characteristics.

Three driving conditions are applied to each controlled semiactive suspension and to the passive suspension. The driving conditions are (a) the BSST (Bounce Sine Sweep Test), which evaluates the vehicle suspension to measure the road holding over continually varying frequencies ranging from 0 to $20 \mathrm{~Hz}$, (b) the BOGGS (after the test used by Boggs et al. [20]) test, which evaluates the road holding over discrete frequencies during five cycles, ranging from 0 to $20 \mathrm{~Hz}$, and (c) a double $1.5 \mathrm{~m}$ motocross jump. The driving condition considers two motorbike-operation scenarios: (a) a constant speed of $60 \mathrm{kph}$ and (b) full throttle acceleration. Besides, the three tests described above will be performed with and without taking into account the transient behavior (Figure 5 without and without the filter). The frequency response of the tire deflection transfer function over road and a quantitative index shows each suspension performance. The tested frequencies represent the typical operation range of a vehicle suspension.

The qualitative performance evaluation of road holding improvement is based on the tire deflection versus road transfer function frequency response, as road holding is the main objective in a competition, whereas the performance of an $\mathrm{EH}$ damper is compared on how a semiactive shock absorber would behave compared to the bike's passive damper. Less magnitude is better. The qualitative performance evaluation of each control method with dynamic force response shows the damping force requirement versus time with and without filter. The damper characteristics plot shows the qualitative performance evaluation of each control method exploiting the $\mathrm{EH}$ damper.

For the quantitative analysis, an approximation of Spelta's and Delvecchio's et al. performance index $\left(P_{i}\right)$ is employed, which provides a fair estimate of the achievable handling [14]:

$$
P_{i}=\sum_{t 1}^{t n}\left(z_{t i}^{2}\right) .
$$




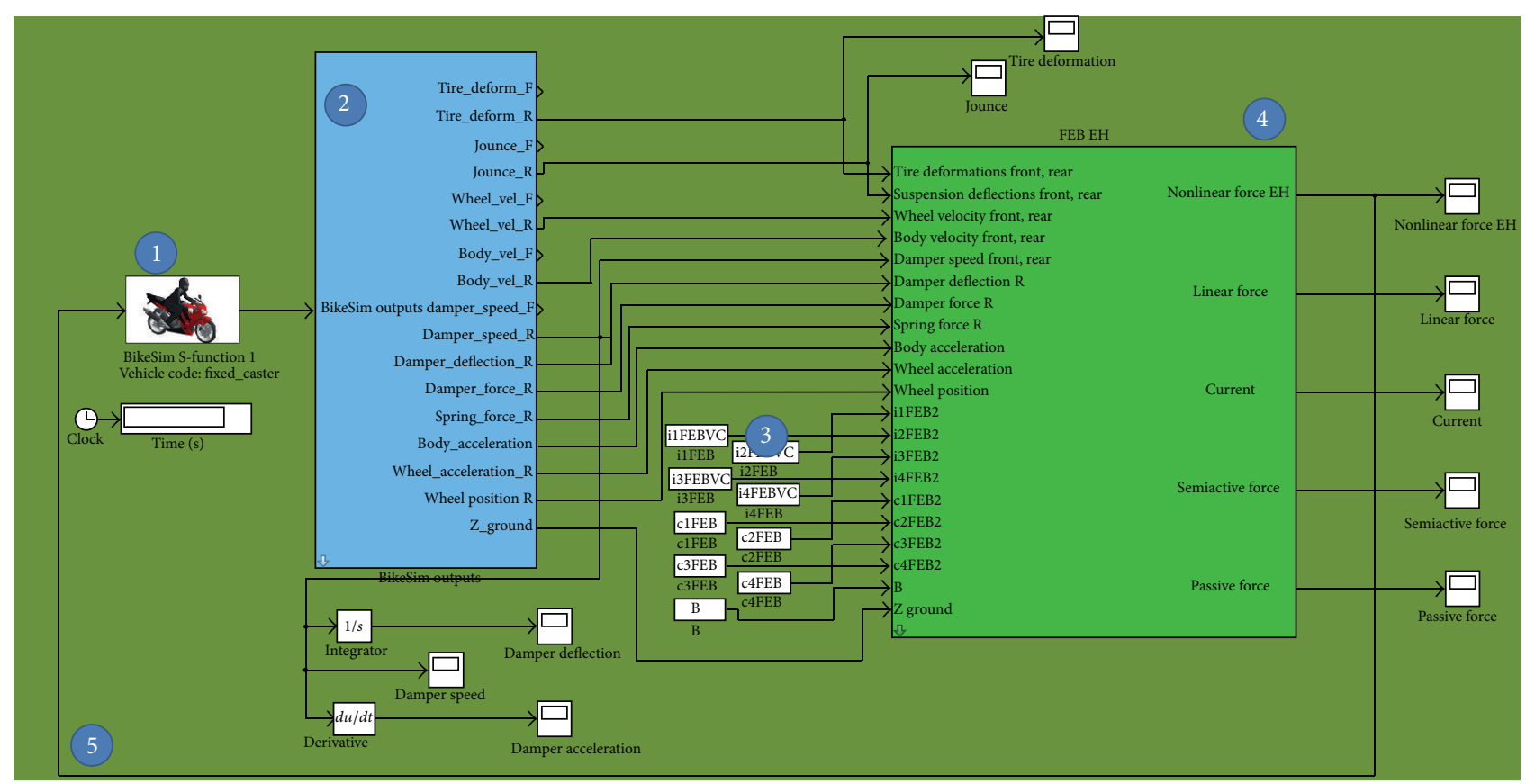

Figure 3: BikeSim-Matlab model.

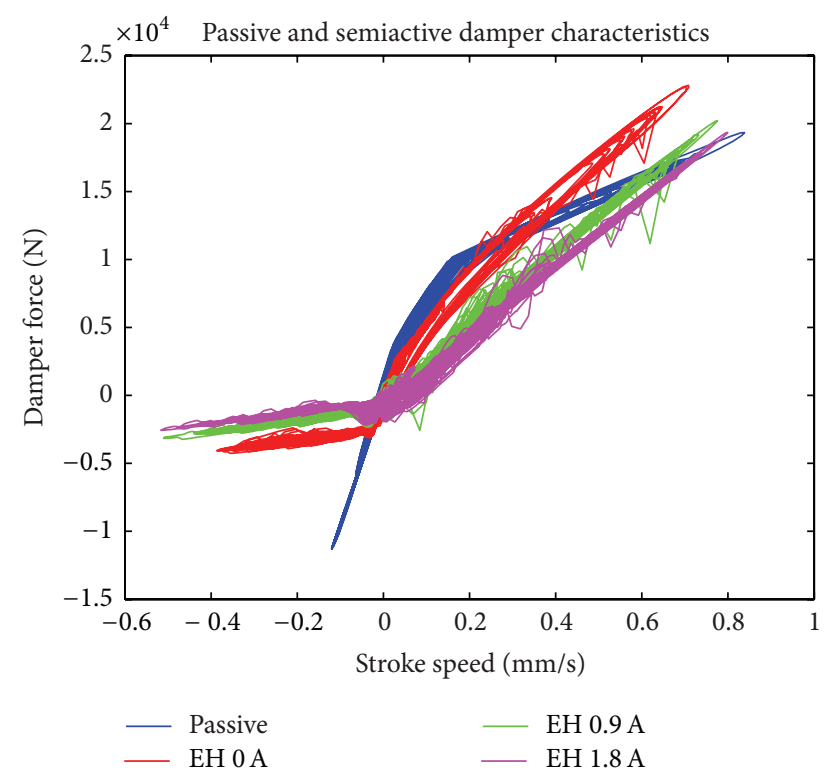

FIGURE 4: EH and passive damper characteristics.

The improvement in the road holding performance due to each semiactive suspension control system is quantified with an improvement index $\left(I_{i}\right)$ :

$$
I_{i}=\frac{\left(P_{i \text { Passive }}-P_{i \text { Controlled }}\right)}{P_{i \text { Passive }}} .
$$

The described methodology is done for the EH damper model with and without filter in order to observe the static and dynamic performance of the control systems. The filter

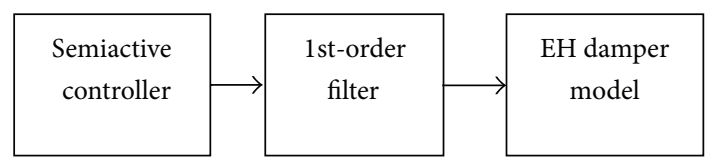

FIGURE 5: Dynamic transient behavior simulation.

adds realism to the simulation. In this manner, two sets of qualitative and two sets of quantitative (with and without filter) results will be discussed. 


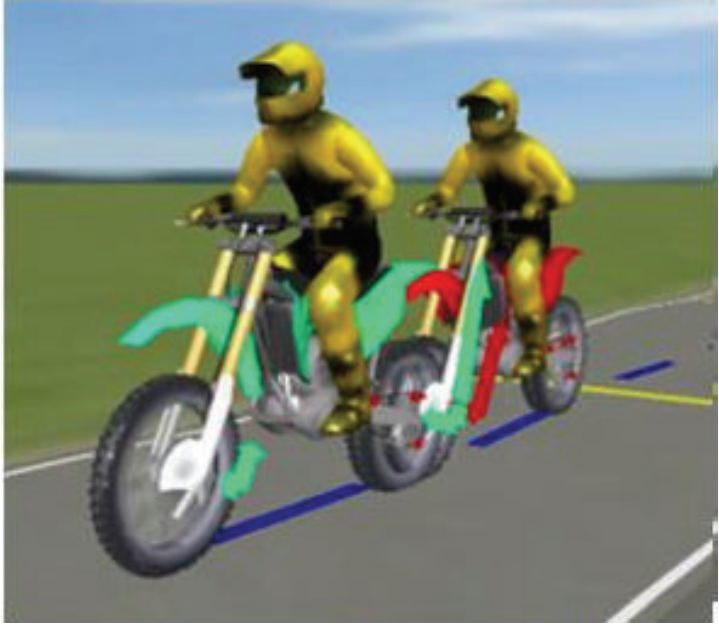

(a) BSST at constant speed: FEB controller (left) and SH-ADD (right)

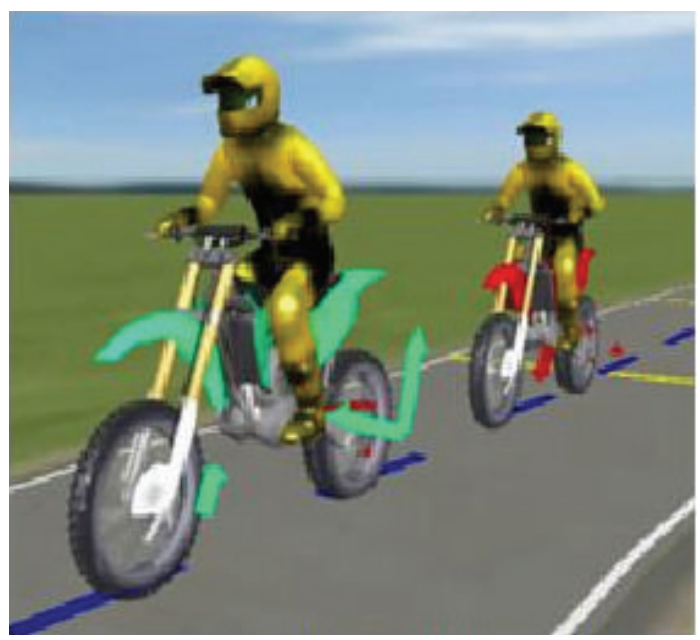

(b) BSST at constant acceleration: FEB controller (left) and Mixed SH-ADD controller (right)

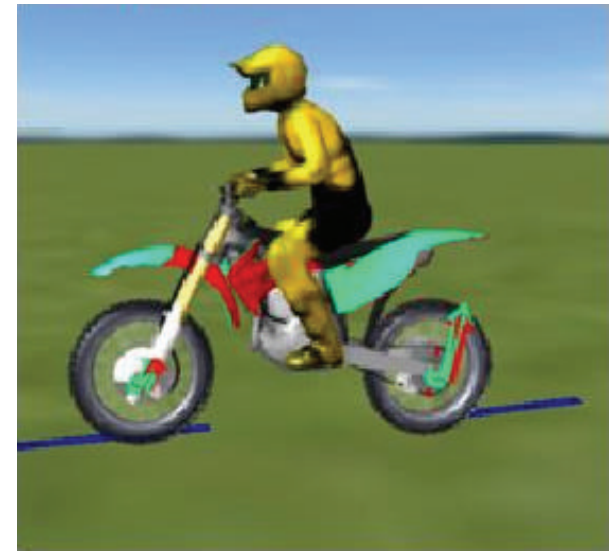

(c) BOGGS test at constant speed: FEB controller versus Mixed 1 Sensor (similar performances)

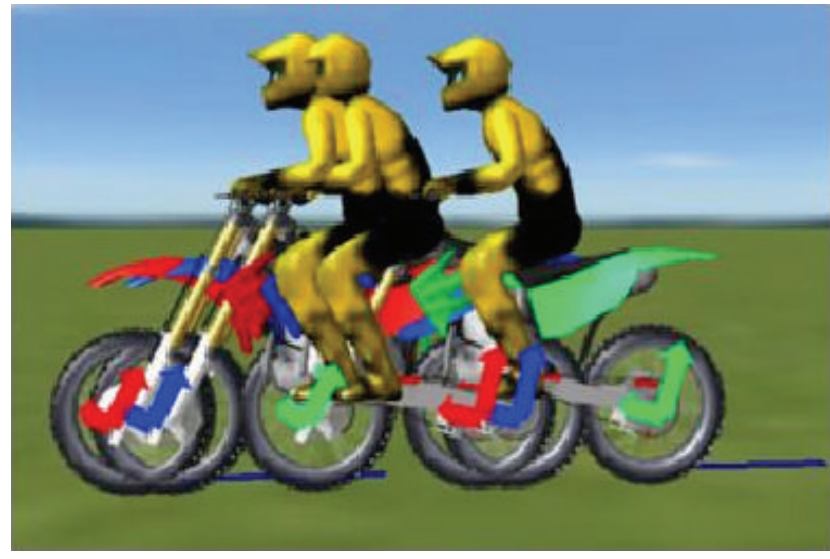

(d) BOGGS test at constant acceleration: Mixed-Handling controller (left) versus FEB controller (middle) versus Mixed 1 Sensor (right)

FIGURE 6: Motorcycle with different semiactive suspensions.

\section{Results}

The simulation of the tests was done. Figure 6 shows an animation of the tests for the different control strategies.

5.1. Qualitative Results. The best control methods during the simulation tests were the Mixed-Handling and FEB which were compared to the passive damper in each plot. The LQR method is added to each plot for comparative purpose only since it does not improve road holding. Figure 7 shows the frequency response of the transfer function tire deformation over the road profile for constant speed (top) and constant acceleration (down) for BSST. Figure 8 shows the frequency response of the transfer function tire deformation over the road profile for constant speed (top) and constant acceleration (down) for BOGGS test.

In the BSST with a constant speed of $60 \mathrm{kph}$, the FEB controller equipped motorbike outperformed the passive damper and the Mixed-Handling motorcycles. Figure 6(a) shows the computer simulation and Figure 7 (top) shows less tire deflection when using semiactive technology.

In the BSST with constant full throttle acceleration passive damper, the FEB controller provided a greater advantage, Figure 6(b). Similar to the constant speed test, Figure 7 (bottom) data shows less tire deflection when using semiactive technology.

During the BOGGS test with constant $60 \mathrm{kph}$ speed, Figures 6(c) and 8 (top), the FEB control presented the lowest gain in the interest bandwidth of the road holding.

In constant full throttle acceleration, Figures 6(d) and 8 (bottom), the controllers did not improve road holding and their behavior was very similar. Qualitative frequency response in Figure 8 shows that the semiactive approaches are better in some sections of the test, overall for low frequencies.

The dynamic response of three controllers for the BSST with constant speed shows that the manipulation of the damping of the FEB control method does not change due to the filter while other method's outputs are totally attenuated 


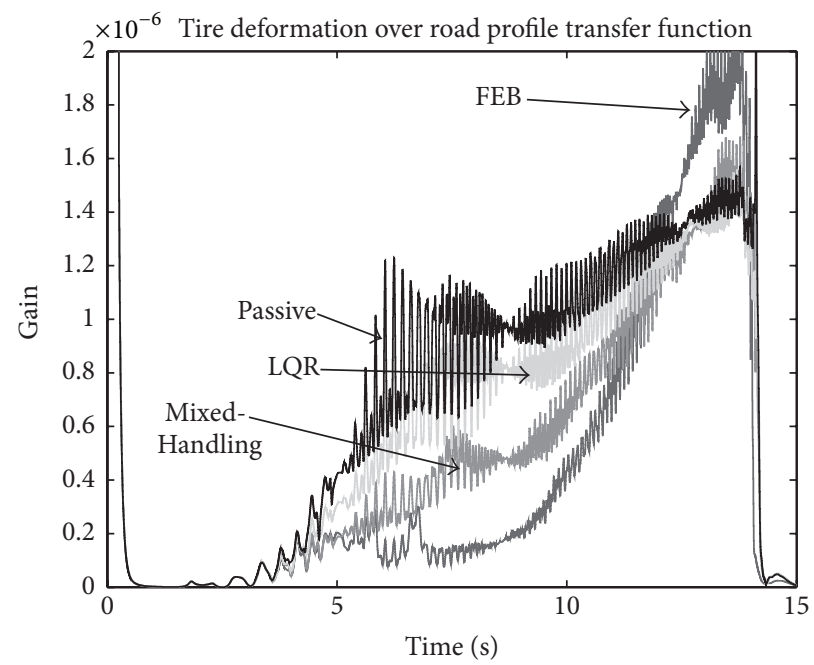

(a)

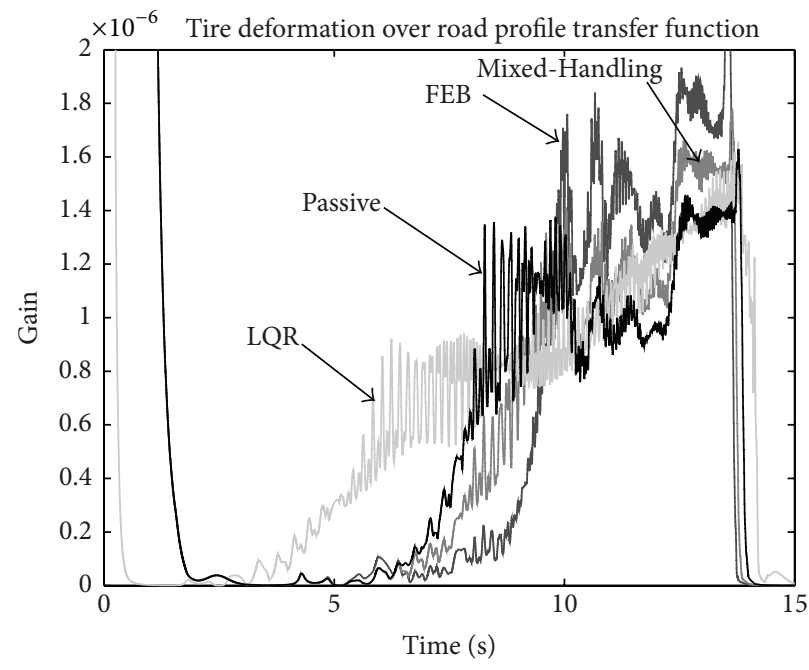

(b)

FIGURE 7: BSST: constant speed (top) and constant acceleration (bottom) tire deformation over the road.

due to the high frequency bandwidth of the computed output. The FEB control method computes a low bandwidth manipulation independently of the damper characteristic, Figure 9 (top and bottom).

The EH damper characteristics with and without filter, Figure 10, compare the force-velocity plot of the FEB and Mixed-Handling methods for the BSST with a constant speed. During the BSST with constant speed, the damper characteristics were better exploited by the FEB controller with and without filter, Figure 10 (bottom), because it applied high and low forces independently of the damper rod speed at low frequency. The Mixed-Handling controller, Figure 10 (top), kept the damper in on mode (high damping) most of the time. The high frequency force transitions from low to high and vice versa, Figure 10 (top), generated by the Mixed-Handling were too fast when the filter is added. This controller could not be feasible in a real application for offroad motorcycle.
5.2. Quantitative Results. All the evaluated controllers are presented in four tables. Each table contains the improvement performance with and without filter in comparison to the passive suspension. Each table marks with bold font the best two controllers for the frequency bandwidth presented in a definite interval of time. The BSST with constant $60 \mathrm{kph}$ speed, Table 2, indicates that the Mixed SH-ADD is better for low frequencies and the FEB for high frequencies. Results in the BSST with constant full throttle acceleration, Table 3, showed the same results.

The BOGGS test with constant $60 \mathrm{kmh}$ speed, Table 4, shows that the Mixed-Handling control offers an average $16 \%$ improvement increase against a passive damper in all frequency bandwidth. This was true for both cases, with and without filter.

When the test was done with constant full throttle acceleration, Table 5, the FEB control improved the road holding with and without filter with an average $15 \%$ index. 


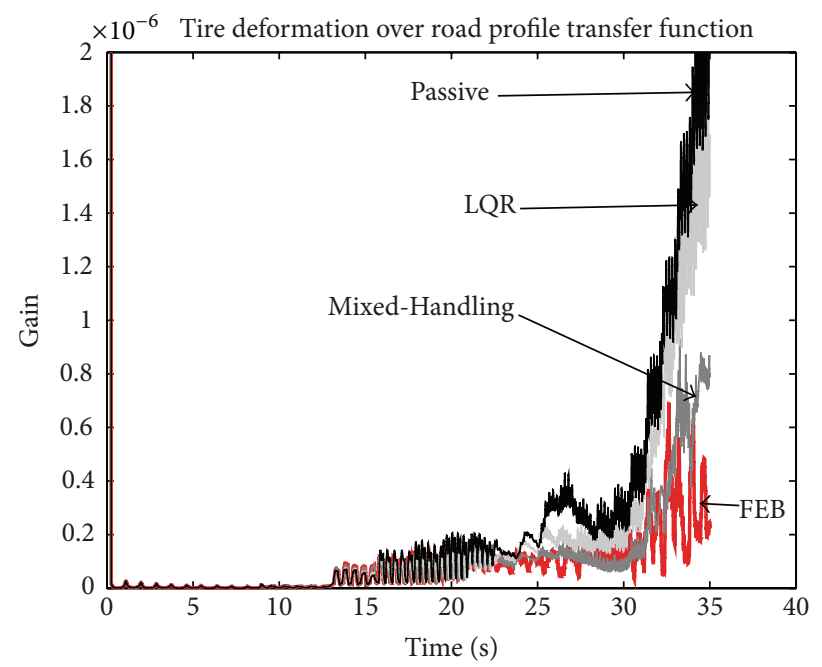

(a)

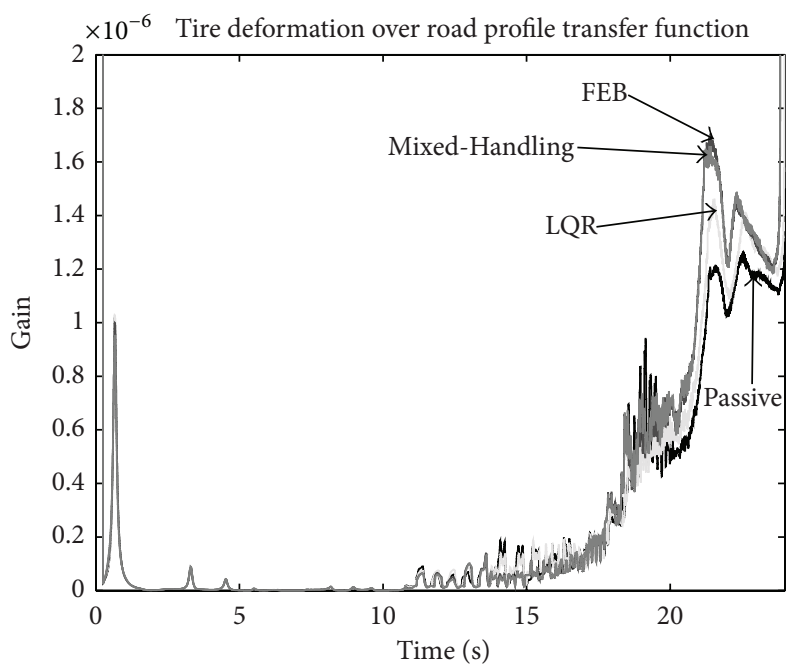

(b)

FIGURE 8: BOGGS test results: constant speed (top) and constant acceleration (bottom) tire deformation over the road.

TABLE 2: BSST, constant speed improvement index (higher is better).

\begin{tabular}{|c|c|c|c|}
\hline \multirow{4}{*}{$\begin{array}{l}\text { Damper/damper } \\
\text { control }\end{array}$} & \multicolumn{3}{|c|}{ Time (seconds) } \\
\hline & $0-3.8$ & $3.8-5.7$ & $5.7-13.8$ \\
\hline & \multicolumn{3}{|c|}{ Frequency $(\mathrm{Hz})$} \\
\hline & 4 & 10 & 11 \\
\hline \multicolumn{4}{|c|}{ Without filter } \\
\hline Mixed SH-ADD & 0.45 & 0.57 & 0.58 \\
\hline FEB & 0.44 & 0.58 & 0.62 \\
\hline LQR continuous & 0.45 & 0.46 & 0.52 \\
\hline \multicolumn{4}{|c|}{ With filter } \\
\hline Mixed SH-ADD & 0.44 & 0.56 & 0.59 \\
\hline FEB & 0.45 & 0.58 & 0.63 \\
\hline LQR continuous & 0.45 & 0.46 & 0.52 \\
\hline
\end{tabular}

Finally, the motocross jump test showed the areas of opportunity of the semiactive shock absorbers. The passive damper easily outperformed every control approach in both constant speed and constant acceleration test. This will be further discussed in the following section.

\section{Discussion}

Information on the BSST positions the FEB controller as the best alternative in road holding, with less tire deformation variations over the road and an overall better road holding performance index in both tests.

In the BOGGS tests, the FEB and Mixed-Handling controllers were consistently the best alternatives. The MixedHandling controller outperformed the rest at constant speed. When road frequency changes are fast due to acceleration, the Mixed-Handling controller computes faster changes than in the constant speed test, but the dynamic response of the $\mathrm{EH}$ damper is not as fast as the requested damping changes. In contrast, as the FEB controller works by bandwidths, 


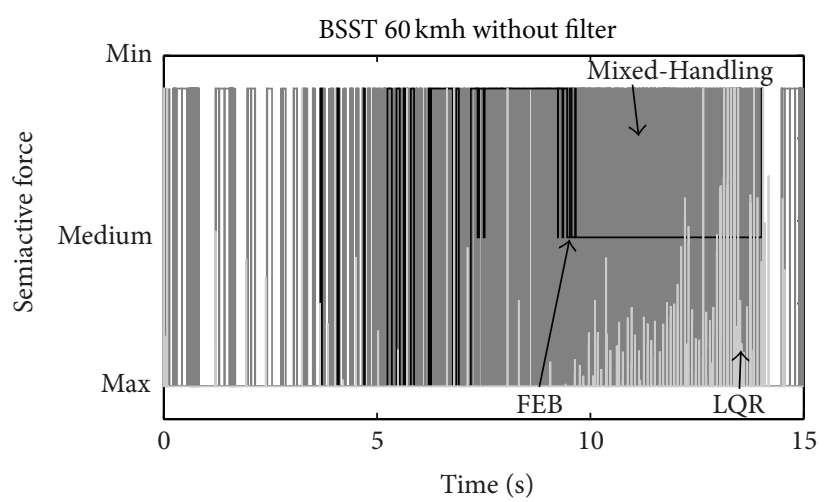

(a)

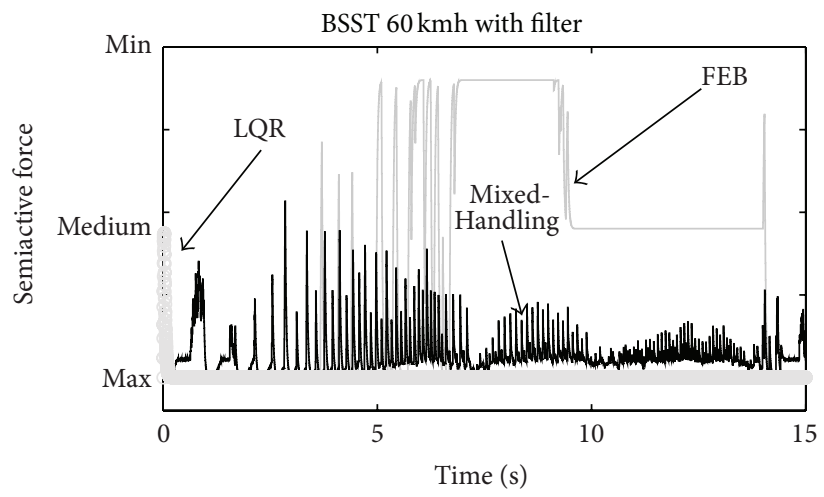

(b)

FIgURE 9: Static and dynamic response of the damper in BSST for constant speed and three controllers.

TABLE 3: BSST, full throttle acceleration improvement index (higher is better).

\begin{tabular}{|c|c|c|c|c|}
\hline \multirow{4}{*}{ Damper/damper control } & \multicolumn{4}{|c|}{ Time (seconds) } \\
\hline & $0-5.65$ & $5.65-7.2$ & $7.2-7.9$ & $7.9-10.6$ \\
\hline & \multicolumn{4}{|c|}{ Frequency $(\mathrm{Hz})$} \\
\hline & 4 & 10 & 16 & 33 \\
\hline \multicolumn{5}{|c|}{ Without filter } \\
\hline Mixed SH-ADD & 0.56 & 0.57 & 0.46 & 0.49 \\
\hline FEB & 0.54 & 0.58 & 0.59 & 0.56 \\
\hline LQR continuous & 0.55 & 0.54 & 0.37 & 0.45 \\
\hline \multicolumn{5}{|c|}{ With filter } \\
\hline Mixed SH-ADD & 0.56 & 0.55 & 0.47 & 0.50 \\
\hline FEB & 0.54 & 0.58 & 0.59 & 0.56 \\
\hline LQR continuous & 0.55 & 0.54 & 0.37 & 0.44 \\
\hline
\end{tabular}

the manipulation (requested damping) bandwidth remains in the low frequency interval and accomplishes the dynamic response in the $\mathrm{EH}$ damper.

If the semiactive damper presents a fast response, the control performance is better. This is a current constraint in damping technology for off-road applications or for speed bikes. Large deflections of the suspension (relative to the speed motorbikes category) at high frequencies $(6-12 \mathrm{~Hz})$ increase the temperature inside the piston. This represents a challenge to the design of semiactive dampers for off-road motorbikes.
The results of this simulation confirm that, by using a semiactive damper in an off-road motorbike, a performance increase can be achieved. The results of the first two tests show how the damper is affected by the vehicle speed and road frequency, and by using different control schemes it can be adjusted to operate differently under predefined conditions. The FEB controller offers the best advantage by being able to adjust damping force continuously instead of switching between two damping states with a low frequency bandwidth.

Finally, the double 1.5-meter jump test showed that the $\mathrm{EH}$ damper used in the experiments cannot outperform 


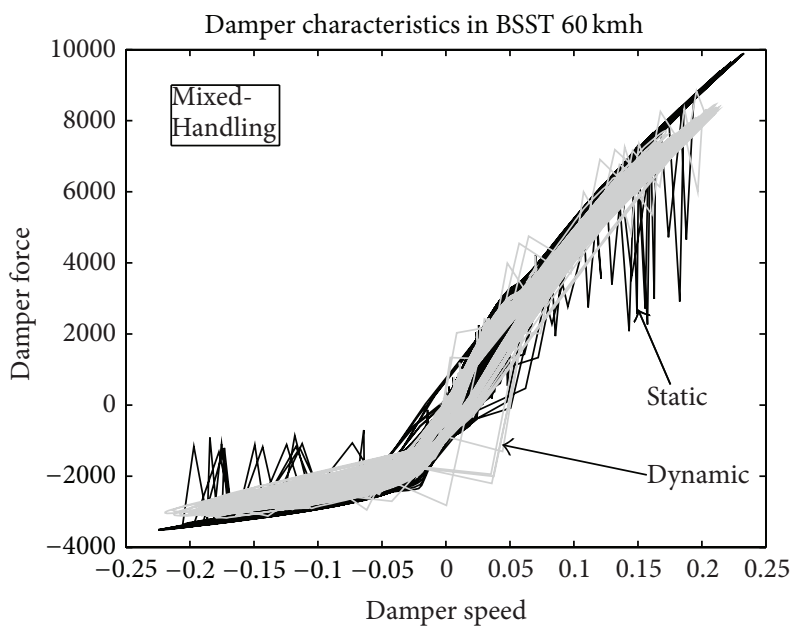

(a)

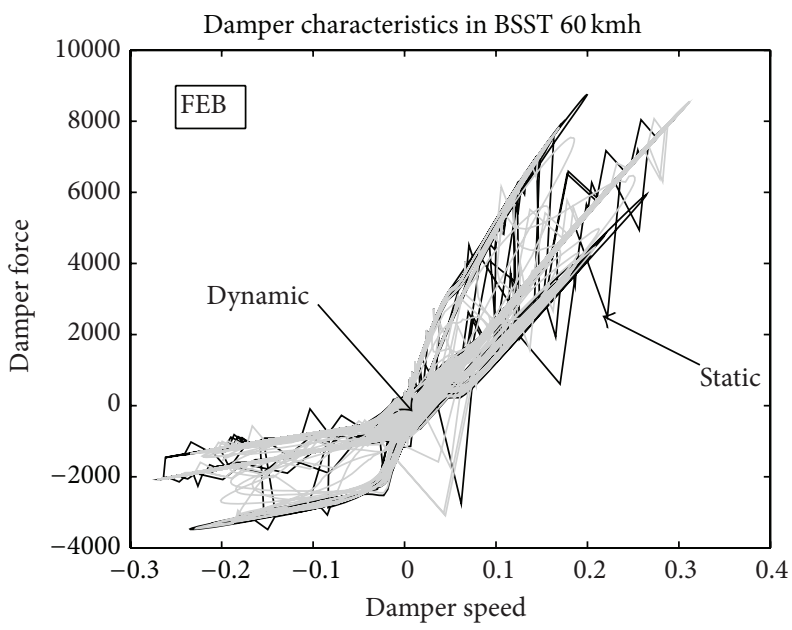

(b)

FIGURE 10: Damper characteristics (static and dynamic) in BSST for constant speed and two controllers.

TABLE 4: BOGGS test, constant speed improvement index (higher is better).

\begin{tabular}{|c|c|c|c|c|c|}
\hline \multirow{4}{*}{ Damper/damper control } & \multicolumn{5}{|c|}{ Time (seconds) } \\
\hline & $22.6-23.9$ & $26.5-27.7$ & $28.6-29.65$ & $31.8-32.8$ & $32.8-35.3$ \\
\hline & \multicolumn{5}{|c|}{ Frequency (hertz) } \\
\hline & 3.85 & 4.17 & 4.76 & 5.00 & 5.56 \\
\hline \multicolumn{6}{|c|}{ No filter } \\
\hline $\mathrm{GH}$ & 0.02 & -0.01 & -0.03 & 0.08 & 0.01 \\
\hline Mixed-Handling & 0.17 & 0.25 & 0.18 & 0.32 & 0.15 \\
\hline Mixed 1 Sensor & -0.03 & -0.08 & 0.03 & 0.07 & -0.03 \\
\hline FEB & -0.07 & 0.08 & 0.03 & 0.16 & -0.06 \\
\hline LQR continuous & -0.01 & -0.10 & -0.12 & -0.01 & -0.25 \\
\hline \multicolumn{6}{|c|}{ With filter } \\
\hline $\mathrm{GH}$ & 0.05 & -0.06 & -0.13 & -0.01 & 0.01 \\
\hline Mixed-Handling & 0.19 & 0.24 & 0.08 & 0.26 & 0.15 \\
\hline Mixed 1 Sensor & -0.01 & 0.10 & -0.06 & 0.01 & -0.05 \\
\hline FEB & 0.02 & -0.03 & -0.14 & 0.06 & 0.15 \\
\hline LQR continuous & -0.07 & -0.06 & -0.15 & -0.15 & -0.28 \\
\hline
\end{tabular}


TABLE 5: BOGGS test, full throttle acceleration improvement index (higher is better).

\begin{tabular}{|c|c|c|c|c|c|}
\hline \multirow{4}{*}{ Damper/damper control } & \multicolumn{5}{|c|}{ Time (seconds) } \\
\hline & $10.45-11.8$ & $11.8-12.75$ & $12.75-13.48$ & $13.48-14.05$ & $14.05-14.53$ \\
\hline & \multicolumn{5}{|c|}{ Frequency (hertz) } \\
\hline & 3.70 & 5.26 & 6.85 & 8.77 & 10.42 \\
\hline \multicolumn{6}{|c|}{ Without filter } \\
\hline GH & 0.01 & 0.01 & 0.00 & -0.02 & 0.01 \\
\hline Mixed-Handling & 0.39 & -0.21 & 0.17 & 0.21 & 0.27 \\
\hline Mixed 1 Sensor & 0.00 & -0.01 & 0.00 & -0.01 & -0.02 \\
\hline FEB & 0.23 & 0.03 & 0.15 & 0.18 & 0.29 \\
\hline LQR continuous & -0.02 & 0.13 & 0.16 & -0.10 & -0.13 \\
\hline \multicolumn{6}{|c|}{ With filter } \\
\hline $\mathrm{GH}$ & -0.08 & 0.01 & -0.05 & -0.05 & -0.04 \\
\hline Mixed-Handling & 0.31 & -0.16 & 0.12 & 0.16 & 0.27 \\
\hline Mixed 1 Sensor & -0.02 & 0.01 & -0.02 & -0.06 & -0.07 \\
\hline FEB & 0.15 & 0.03 & 0.10 & 0.14 & 0.29 \\
\hline LQR continuous & -0.11 & 0.12 & 0.06 & -0.07 & -0.04 \\
\hline
\end{tabular}

a passive one designed and optimized for motocross events. This is largely because semiactive technology was not developed for this particular sport, in which a damper is subjected to strong and constant impacts. It would require a specially designed semiactive shock absorber, validated mechanically and electronically using the V-Model approach to be used in these kinds of sports.

Future work as a continuation of this paper should involve the use of a semiactive suspension designed to withstand the competition's demands, as well as a study of the motorbike's behavior in a complete motocross track.

\section{Conclusion}

This paper has evaluated several semiactive suspension control systems in a new environment: an off-road motorbike. The results confirm that a performance increase can be obtained by using this technology, but at the same time it is limited to selected events due to the dependency of the vehicle suspension behavior on road frequencies and speed conditions.

Among the control systems, the FEB algorithm is the one with a wider field of applications, by giving the user the ability to continuously customize the damper behavior under different road conditions, instead of relying on an on/off switch.

\section{Abbreviation}

\section{Variable Description}

$F_{P}$ : Passive component of the damping force (N)

$F_{\mathrm{SA}}$ : Semiactive component of the damping force $(\mathrm{N})$

$f_{0}$ : Constant damping force $(\mathrm{N})$

$c_{p}$ : Damping coefficient $(\mathrm{Ns} / \mathrm{m})$ $\dot{z}: \quad$ Damper speed (m/s)

$k_{p}: \quad$ Spring coefficient $(\mathrm{N} / \mathrm{m})$

$z: \quad$ Damper deflection $(\mathrm{m})$

$m_{D}: \quad$ Damper body mass $(\mathrm{kg})$

$\ddot{z}: \quad$ Damper acceleration

$f_{s}: \quad$ Sigmoidal damper force $(\mathrm{N})$

$f_{h, z}: \quad$ Sigmoidal damper force with hysteresis due to $z(\mathrm{~N})$

$f_{h, \ddot{z}}: \quad$ Sigmoidal damper force with hysteresis due to $z(\mathrm{~N})$

M: $\quad$ Manipulation (external variable) (A)

$g_{\mathrm{SA}}: \quad$ Semiactive force slope due to manipulation applied (N/(manipulation units))

$f_{\text {pre- } c, \dot{z}, M}$ : Damping force dependent on $\dot{z}(\mathrm{~N})$

$f_{\text {pre }-c, z}: \quad$ Damping force dependent on $z(\mathrm{~N})$

$f_{c, s}$ : $\quad$ Sigmoidal damping force magnitude $(\mathrm{N})$

$r_{s}: \quad$ Sigmoidal damping coefficient $(\mathrm{s} / \mathrm{m})$

$h_{s}: \quad$ Sigmoidal damping coefficient with hysteresis $(1 / \mathrm{m})$

$r_{z}: \quad$ Precedent damping coefficient due to $z$ (s/m)

$h_{z}$ : $\quad$ Precedent damping coefficient with hysteresis due to $z(1 / \mathrm{m})$

$r_{\ddot{z}}: \quad \quad$ Precedent damping coefficient due to $\ddot{z}$ ( $\mathrm{s} / \mathrm{m})$

$h_{\ddot{z}}: \quad$ Precedent damping coefficient with hysteresis due to $\ddot{z}(1 / \mathrm{m})$

$r_{\dot{z}, M}: \quad$ Sigmoidal damping coefficient due to $\dot{z}$ (s/m)

$r_{z, M}: \quad$ Precedent damping coefficient due to $z$ $(\mathrm{s} / \mathrm{m})$

$z_{\text {us }}: \quad$ Unsprung mass $(\mathrm{kg})$

$z_{s}: \quad$ Sprung mass $(\mathrm{kg})$

$\alpha: \quad$ Crossover frequency (Rad)

$\dot{z}_{t}: \quad$ Tire deflection speed ( $\left.\mathrm{mm} / \mathrm{s}\right)$ 


$$
\begin{array}{ll}
z_{t}: & \text { Tire deflection }(\mathrm{mm}) \\
\text { BWn: } & \text { Frequency bandwidth }(\mathrm{Hz}) \\
\gamma n: & \text { Electrical current output }(\mathrm{A}) \\
m_{s} \text { and } m_{\mathrm{us}}: & \text { Sprung and Unsprung masses. }
\end{array}
$$

\section{Conflict of Interests}

The authors declare that there is no conflict of interests regarding the publication of this paper.

\section{Acknowledgment}

The University of Monterrey thanks the support of Mechanical Simulation BikeSim during the course of this research.

\section{References}

[1] E. Gorr and K. Cameron, Four-Stroke Motocross and Off-Road Performance Handbook, MBI Publishing Company, Saint Paul, Minn, USA, 2011.

[2] M. Marquez, Motocross Suspension Setup Guide, 2015, http://service.foxracingshox.com/powersports/Content/MX_suspension_ tuning_guide.htm.

[3] Cadillac, Cadillac Escalade 2015, 2015, http://www.cadillac .com/escalade-suv.html.

[4] Ducati, "Ducati Multistrada 1200," 2015, http://www.ducati .com/bikes/multistrada/index.do.

[5] J. Söderberg, Black-box modeling of a semi-active motorcycle damper [Master thesis], KTH Royal Institute of Technology, Stockholm, Sweden, 2011.

[6] A. Trevitt, Semi-Active Suspension, Sport Rider, 2014, http:// www.sportrider.com/tech/semi-active-suspension.

[7] B. F. Spencer Jr., S. J. Dyke, M. K. Sain, and J. D. Carlson, "Phenomenological model for magnetorheological dampers," Journal of Engineering Mechanics, vol. 123, no. 3, pp. 230-238, 1997.

[8] M. Pelosi, K. Subramanya, and J. Lantz, "Investigation on the dynamic behavior of a solenoid hydraulic valve for automotive semi-active suspensions coupling $3 \mathrm{D}$ and $1 \mathrm{D}$ modeling," in Proceedings of the 13th Scandinavian International Conference on Fluid Power, pp. 241-250, Linköping, Sweden, June 2013.

[9] J. W. Gravatt, Magneto-rheological dampers for super-sport motorcycle applications [M.S. thesis], Virginia Tech, Blacksburg, Va, USA, 2003.

[10] E. O. Ericksen and F. Gordaninejad, "A magneto-rheological fluid shock absorber for an off-road motorcycle," International Journal of Vehicle Design, vol. 33, no. 1-3, pp. 139-152, 2003.

[11] C. Spelta, S. M. Savaresi, and L. Fabbri, "Experimental analysis of a motorcycle semi-active rear suspension," Control Engineering Practice, vol. 18, no. 11, pp. 1239-1250, 2010.

[12] S. M. Savaresi and C. Spelta, "Mixed sky-hook and ADD: approaching the filtering limits of a semi-active suspension," Journal of Dynamic Systems, Measurement, and Control, vol. 129, no. 4, pp. 382-392, 2007.

[13] M. Valášek, M. Novák, Z. Šika, and O. Vaculín, "Extended ground-hook-new concept of semi-active control of truck's suspension," Vehicle System Dynamics, vol. 27, no. 5-6, pp. 289303, 1997.

[14] C. Spelta, D. Delvecchio, R. Cantoni, R. Lazzari, and S. M. Savaresi, "Analysis and design of handling-oriented control strategies for semi-active suspensions," in Proceedings of the 48th IEEE Conference on Decision and Control held jointly with 2009 28th Chinese Control Conference (CDC/CCC '09), pp. 7633-7638, December 2009.

[15] S. M. Savaresi and C. Spelta, "A single-sensor control strategy for semi-active suspensions," IEEE Transactions on Control Systems Technology, vol. 17, no. 1, pp. 143-152, 2009.

[16] J. de Jesus Lozoya-Santos, R. Morales-Menendez, J. TudonMartinez, O. Sename, L. Dugard, and R. Ramirez-Mendoza, "Control strategies for an automotive suspension with a MR damper," in Proceedings of the 18th IFAC World Congress, Milan, Italy, August 2011.

[17] L. H. Nguyen, S. Park, A. Turnip, and K.-S. Hong, "Application of LQR control theory to the design of modified skyhook control gains for semi-active suspension systems," in Proceedings of the International IEEE Conference on Control, Automation and Systems (ICCAS-SICE '09), vol. 1, pp. 4698-4703, IEEE, Fukuoka, Japan, August 2009.

[18] S. Savaresi, C. Poussot-Vassal, C. Spelta, O. Sename, and L. Dugard, Semi-Active Suspension Control Design for Vehicles, Butterworth-Heinemann, 2010.

[19] J. de-J Lozoya-Santos, R. Morales-Menendez, R. RamirezMendoza, J. C. Tudón-Martinez, O. Sename, and L. Dugard, "Magnetorheological damper-an experimental study," Journal of Intelligent Material Systems and Structures, vol. 23, no. 11, pp. 1213-1232, 2012.

[20] C. Boggs, L. Borg, J. Ostanek, and M. Ahmadian, "Efficient test procedures for characterizing MR dampers," in Proceedings of the ASME International Mechanical Engineering Congress and Exposition (IMECE '06), pp. 173-178, November 2006. 

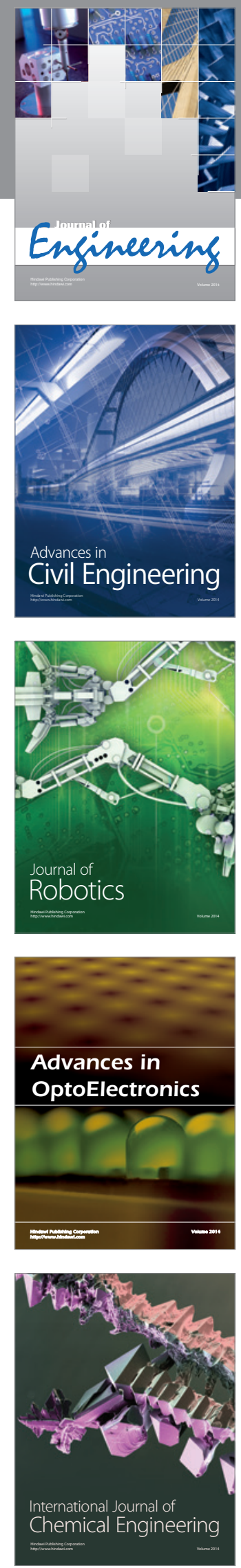

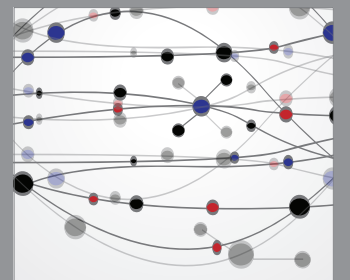

The Scientific World Journal
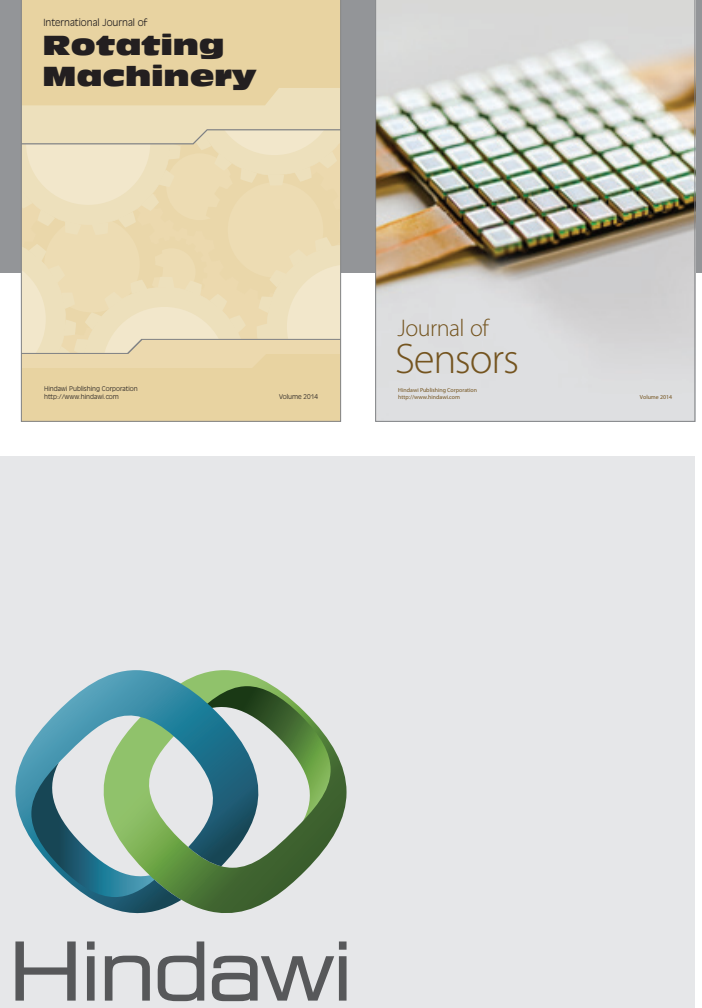

Submit your manuscripts at http://www.hindawi.com
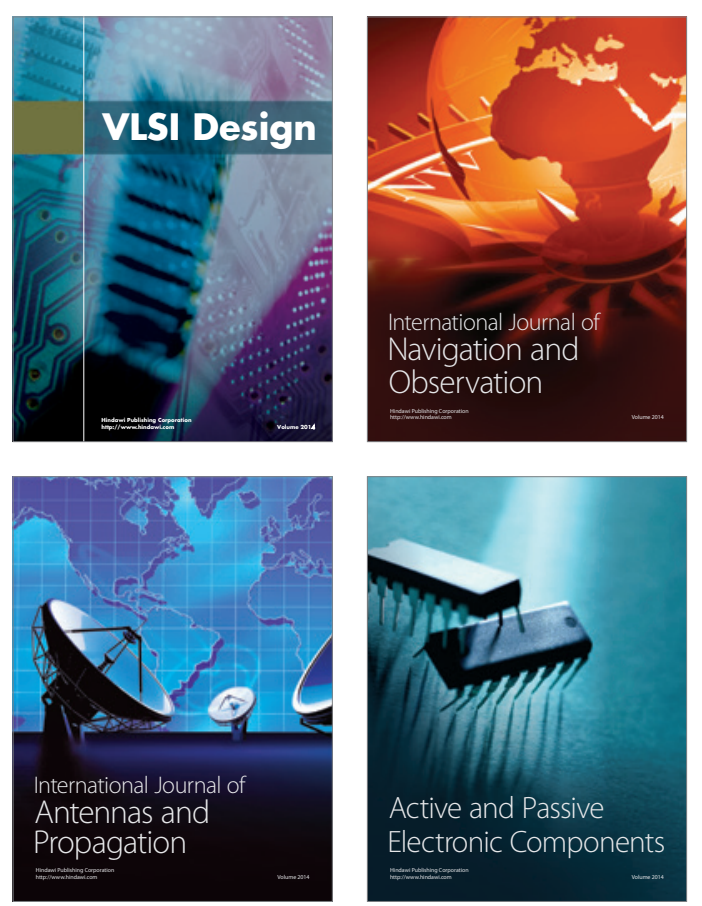
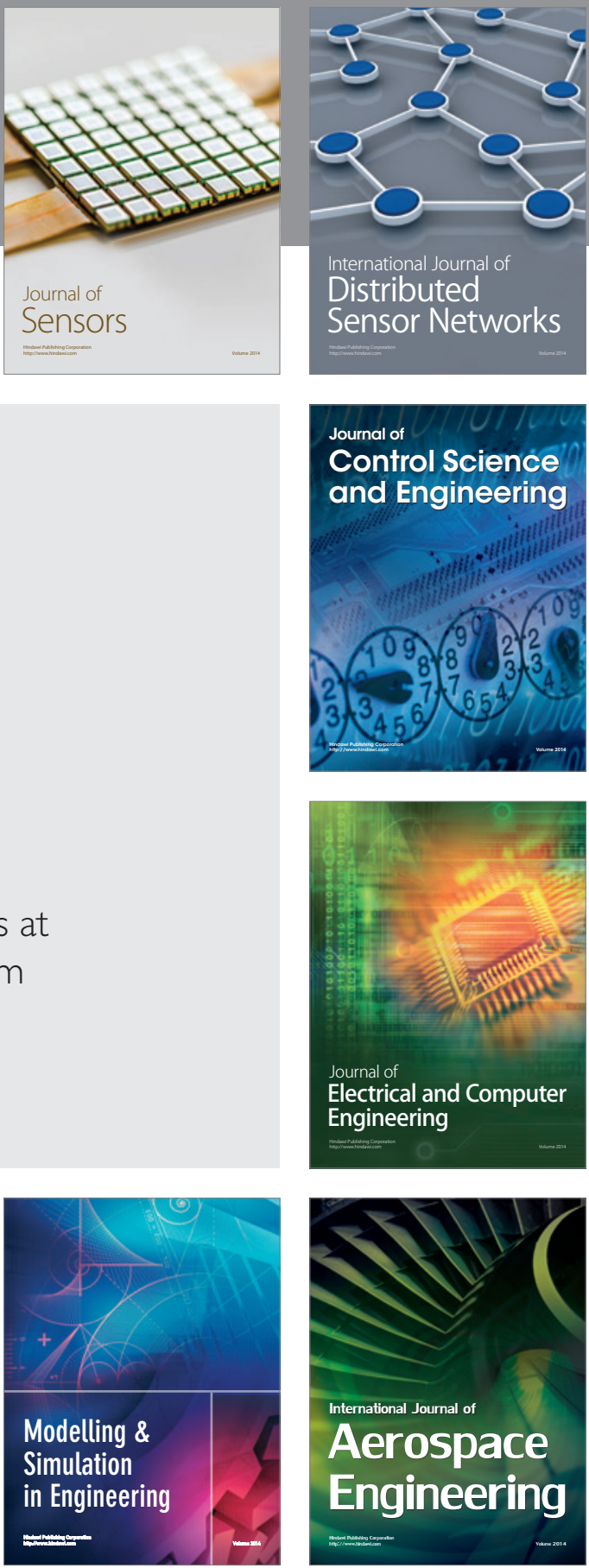

Journal of

Control Science

and Engineering
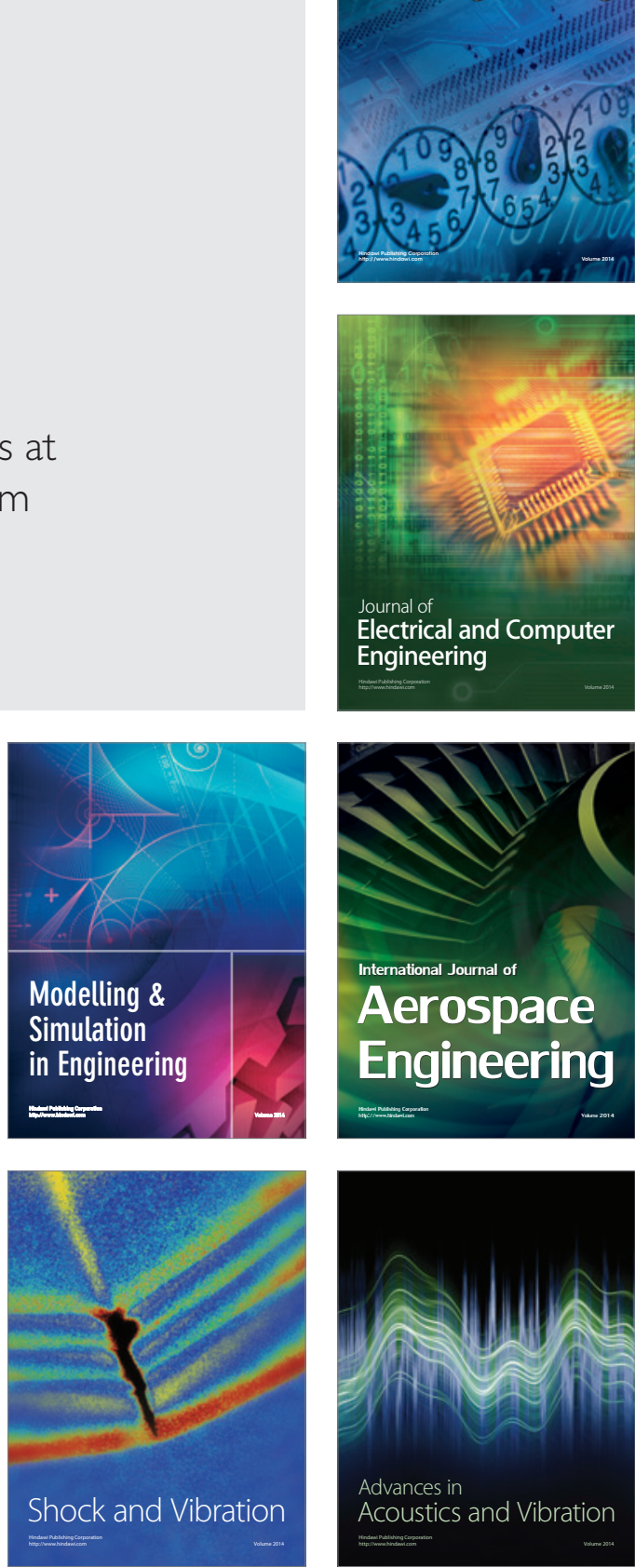